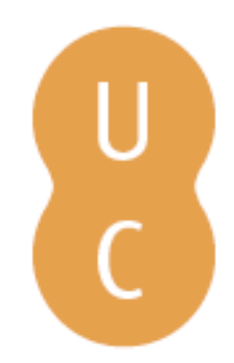

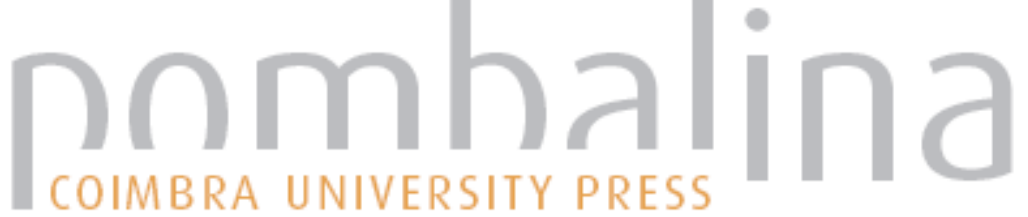

\section{Turismo natureza e riscos na llha da Madeira: avaliação, perceção, estratégias de} planeamento e prevenção

Autor(es): $\quad$ Neves, Daniel; Cunha, Lúcio; Mendes, José Manuel

Publicado por: Imprensa da Universidade de Coimbra

URL

persistente: URI:http://hdl.handle.net/10316.2/37380

DOI: $\quad$ DOI:http://dx.doi.org/10.14195/978-989-26-0754-2_19

Accessed : $\quad$ 26-Apr-2023 12:11:49

A navegação consulta e descarregamento dos títulos inseridos nas Bibliotecas Digitais UC Digitalis, UC Pombalina e UC Impactum, pressupõem a aceitação plena e sem reservas dos Termos e Condições de Uso destas Bibliotecas Digitais, disponíveis em https://digitalis.uc.pt/pt-pt/termos.

Conforme exposto nos referidos Termos e Condições de Uso, o descarregamento de títulos de acesso restrito requer uma licença válida de autorização devendo o utilizador aceder ao(s) documento(s) a partir de um endereço de IP da instituição detentora da supramencionada licença.

Ao utilizador é apenas permitido o descarregamento para uso pessoal, pelo que o emprego do(s) título(s) descarregado(s) para outro fim, designadamente comercial, carece de autorização do respetivo autor ou editor da obra.

Na medida em que todas as obras da UC Digitalis se encontram protegidas pelo Código do Direito de Autor e Direitos Conexos e demais legislação aplicável, toda a cópia, parcial ou total, deste documento, nos casos em que é legalmente admitida, deverá conter ou fazer-se acompanhar por este aviso.

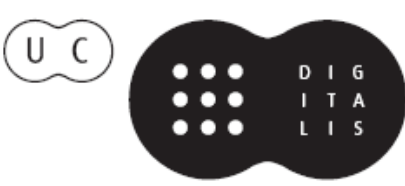




\section{DANIEL NEVES}

Mestre em Dinâmicas Sociais e Riscos Naturais e Tecnológicos daniel.nevespc@gmail.com

\section{LÚCIO CUNHA}

CEGOT, Universidade de Coimbra luciogeo@ci.uc.pt

JOSÉ MANUEL MENDES

CES, Universidade de Coimbra jomendes@fe.uc.pt

TURISMO NATUREZA E RISCOS NA ILHA DA MADEIRA:

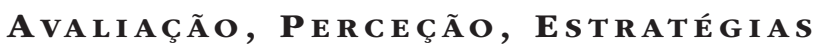
DE PLANEAMENTO E PREVENÇÃo

\section{Introdução}

A visita turística à ilha da Madeira proporciona uma enorme diversidade de atividades, nomeadamente no que diz respeito a atividades desportivas e de lazer. O clima ameno e a orografia peculiar da região convidam à prática de atividades ao ar livre, designadamente a asa delta e o parapente, o BTT, o canyoning, o jeep safari e o trekking nos famosos percursos pedestres, conhecidos pela denominação de "Veredas e Levadas".

Segundo a SRTT (2006), as áreas de maior crescimento no mercado do Turismo na atualidade estão associadas ao ecoturismo, ao turismo de natureza e aventura, bem como a safaris e experiências/vivências locais (com envolvimento nas comunidades visitadas). De acordo com o perfil do turista que procura o destino Madeira, as experiências mais procuradas estão associadas à vivência da natureza (contato e observação da natureza) e férias ativas (Caminhada/Trekking; Mergulho, Sea Watching). 
Em termos demográficos, os turistas que procuram este segmento de mercado turístico, apresentam, na sua maioria, uma idade que varia entre 35-65 anos, tendo-se registado um crescimento nos visitantes com idade superior aos 65 anos (Madeiranature, 2009). Cerca de 82\% dos visitantes têm formação superior, apresentam hábitos de consumo elevado em função dos rendimentos que se caraterizam como médios a altos e utilizam Internet. Saliente-se, também, que se verifica um crescimento forte do visitante reformado. Em comparação com o perfil geral do turista da Madeira, o segmento ligado à Natureza e a férias ativas apresenta-se, apesar de tudo, com maior representação dos mais jovens, uma vez que 54\% dos turistas típicos da Madeira têm mais de 45 anos.

Nas últimas décadas assistimos a grandes mudanças na mentalidade, hábitos e valores da sociedade, e estas alterações fizeram com que o mundo passasse a ser visto pelas pessoas de modo diferente. Fruto destas mudanças, o turismo tem vindo progressivamente a desenvolver-se, produzindo um crescente impato na sociedade e na economia globais e, particularmente, nos estados e regiões arquipelágicas que sempre exerceram sobre as populações continentais uma forte atração. De entre os fatores que determinam a escolha dos destinos turísticos, a segurança desempenha um papel determinante.

Em termos de segurança, os destinos turísticos são escolhidos em função, quer dos índices de criminalidade, quer do risco de ocorrência de desastres naturais, tecnológicos ou sociais, isto é, quanto maior e mais conhecidos forem os casos de incidência de manifestações de risco, menos boa será a imagem e menor será a procura dos destinos por parte de turistas. Mesmo sabendo que, na maior parte das vezes, a ocorrência de desastres naturais ou tecnológicos acontece quando e onde menos se espera, a existência e, sobretudo, a consciência por parte dos visitantes de uma cultura e de condições materiais de segurança é fundamental na criação da imagem turística de um destino. É muito importante que o Ser Humano, antes de mais nada, se sinta seguro e tranquilo no destino que escolheu. A sua perceção de segurança poderá ser reforçada através de ações preventivas e de pro-atividade por parte do sistema de proteção 
civil e das entidades que concorrem para garantir um eficiente sistema de segurança e proteção ao nível local.

Saliente-se que nas diversas modalidades de viagem, desde o seu início até ao retorno ao local de origem, os turistas estão sujeitos a riscos que, se ignorados, podem causar pequenos contratempos, graves complicações ou até mesmo, em casos extremos, levar à morte. Apesar disso, é natural que as pessoas prefiram dar ênfase apenas ao prazer e ao exotismo da viagem e da experiência. Se as agências tendem a valorizar os destinos com apelos promocionais, os turistas procuram um "refúgio" do quotidiano e encontrar o lugar idealizado, mas seguro e sem perigos.

A problemática da segurança e do risco no turismo tem vindo, assim, a adquirir maior expressão nos tempos recentes. A noção da segurança no turismo integra distintos domínios, desde a segurança pública até à segurança ambiental, incluindo a segurança médica e a segurança informativa, entre outros. Enquanto conceito central no estudo do turismo, a segurança tem sido especialmente questionada internacionalmente desde o acontecimento de 11 de Setembro de 2001 nos EUA. Outros exemplos estão nos constrangimentos recentemente criados nos aeroportos da Grã-Bretanha, Noruega e Suécia devido a nuvem de fumo provocada pela erução do vulcão no glaciar Eyjafjllajokull, bem como na trágica aluvião na Madeira no passado dia 20 de Fevereiro de 2010, os quais vieram tornar mais evidente a vulnerabilidade do território. No caso da Madeira, houve a necessidade de o poder político adotar estratégias de gestão do risco e, sobretudo, de comunicação no sentido de diminuir o impato negativo para o exterior e, por conseguinte, reproduzir uma imagem de segurança do destino Madeira.

$\mathrm{Na}$ atualidade, a segurança desempenha um papel vital enquanto elemento estruturante das relações a diferentes níveis: sociais, culturais, económicas, políticas, entre outras. Desta forma, pensar a segurança, em termos gerais ou específicos, significa ter presente a ideia de que existe uma multiplicidade de olhares que permitem equacionar e sentir o "valor segurança” em diferentes dimensões ou perceções.

Optando por uma linha de orientação que privilegia a perceção e sentimento de segurança enquanto fatores de escolha de um destino 
turístico, com base na evidência de que a Ilha da Madeira constitui um destino de excelência no panorama mundial e que, em simultâneo, a economia regional se encontra fortemente dependente da atividade turística (Governo de Portugal, 2007), torna-se importante perceber a forma como o turista internacional perceciona a gestão do risco, nomeadamente nas atividades de turismo de natureza e aventura.

\section{Riscos e atividades de turismo natureza e aventura}

Grande parte da atração das modalidades ligadas ao turismo ativo ou de aventura está exatamente no fato de a sua prática envolver um certo grau de risco. Apesar de se tratar de um risco calculado e, quase sempre,

gerido por profissionais, é a esse risco que se vai buscar a adrenalina que motiva e incita à prática.

Para se entender o grau de importância que tem a gestão de riscos aplicada à segurança do turista no turismo de aventura, é importante analisar o registo histórico dos acidentes relacionados com a sua prática. Para se ter uma noção da situação da segurança oferecida no turismo de aventura, é necessária uma análise com particular incidência nos seguintes elementos de qualificação:

- Tipo de público que contabiliza maior número de acidentes (sexo, idade, nacionalidade);

- Principal consequência dos acidentes (tipo de lesões);

- Necessidade ou não de bospitalização;

- Tipo de falhas que surgem como o principal fator de ocorrência de acidentes;

- Tipo de prática da atividade (prática por conta própria, através de agência de turismo);

- Tipo de procedimentos mais comuns no socorro imediato à vítima (feito no próprio local ou encaminhado para o hospital).

A segurança no turismo de aventura é uma função complexa que envolve pessoas (tanto os clientes ou utentes quanto os prestadores de 
serviços), equipamentos, procedimentos, sistemas de gestão das empresas prestadoras de serviços, dispositivos legais e sistemas de fiscalização e controle existentes em cada município, articulações e logísticas locais disponíveis para buscas e salvamentos e atendimentos médicos, fatores relacionados com o clima e, evidentemente, os perigos existentes em cada atividade associados às condições naturais da sua prática (topografia e variações meteorológicas).

Sabe-se, também, que a efetiva implantação de um sistema de gestão do risco depende, não só do comportamento das próprias empresas prestadoras dos serviços, mas também do de um conjunto largo de instituições, em que o poder público tem um papel relevante, não só como orientador, regulador e fiscalizador, mas especialmente no que diz respeito aos sistemas de busca, salvamento e atendimento médico, em caso de emergências declaradas.

De uma forma geral, os registos atualmente existentes para a Ilha da Madeira mostram que a frequência de ocorrências graves parece não ter relação direta com o grau de risco das atividades. Por exemplo, a primeira categoria de vítimas, incluindo vítimas mortais, é a de pessoas perdidas. A causa parece estar na falta de capacidade de orientação ou na ausência de equipamento próprio para este tipo de situações. Outra categoria de desastres verificada com elevada frequência resulta da falta de planeamento e avaliação de dificuldades por pessoas, individualmente ou em grupo, que se deslocam sem apoio ou orientação especializada. Nestes casos, as causas de incidente, acidente ou morte são a falta de alimentos, de remédios e de vestuário adequados, resultando em desidratação, hipotermia, fraturas, etc.

Segundo uma lista elaborada pela Fear, da Survival Education Association/Sierra Club, fundada em 1892, a nível global, as 10 mais frequentes causas de ocorrências que necessitaram de atuação de equipas de busca e salvamento foram:

- Roupa e calçados inadequados;

- Cansaço (por má avaliação do esforço necessário);

- Sede, desidratação; 
- Hipotermia, inclusive por desconhecimento das suas causas;

- Má avaliação da dificuldade de uma atividade e das próprias habilidades;

- Alimentação inadequada;

- Pouco ou nenbum planeamento;

- Itinerário não comunicado para terceiros;

- Falta de capacidade física, psíquica ou ambiental para lidar com problemas;

- Clima (falta de roupa adequada em casos de mudança brusca de tempo).

É habitual distinguir as causas das ocorrências em atividades de maior risco entre erros de procedimentos e falha dos equipamentos. Além destas categorias, tratando-se de atividades ao ar livre, é necessário contar com os fatores meteorológicos. Desta forma, para evitar que os acidentes ocorram, é necessário que as empresas e agências de turismo especializadas em turismo de aventura definam estratégias de gestão do risco, no sentido de atender com rapidez e eficácia a situações de emergência, oferecendo um produto seguro e com qualidade que contribua, ao mesmo tempo, para o aumento da procura.

Devido ao caráter complexo das atividades de turismo de aventura, a questão da informação é extremamente relevante, principalmente no que diz respeito à subjetividade do termo "aventura" no entendimento de cada cliente ou potencial cliente. Além disso, a disponibilização de informação rigorosa sobre o tipo de atividades a praticar tem sido considerada um fator importante na minimização de acidentes e na transparência da relação com os consumidores, particularmente no cenário internacional.

No domínio da segurança, as medidas de contingência passam pela definição de ações preventivas e/ou corretivas a serem adotadas quando da sinalização ou da ocorrência de acidentes. Neste sentido o guia/monitor de turismo de natureza e aventura deve, de acordo com a legislação específica, ser capaz de assumir as responsabilidades pertinentes, planear itinerários e medidas de emergência, solicitar o socorro, planear alternati- 
vas em caso de mau tempo ou outros aspetos inesperados, decidir sobre alterações na programação da atividade em função de perigos e riscos, garantir o uso adequado de equipamentos, liderar grupos (estabelecer limites claros de comportamento e de independência dos participantes), enfim, assegurar o bem-estar e zelar pela segurança física e emocional dos clientes através da avaliação de fatores que contribuam para acidentes. Assim, deve também observar sinais de desgaste físico e emocional, recomendar alimentação e vestuário adequados à atividade, gerir situações de emergência, assegurar o fornecimento de informações sobre medidas de emergência consideradas e aplicar técnicas de primeiros socorros adequadas a cada situação, se isso se vier a revelar necessário.

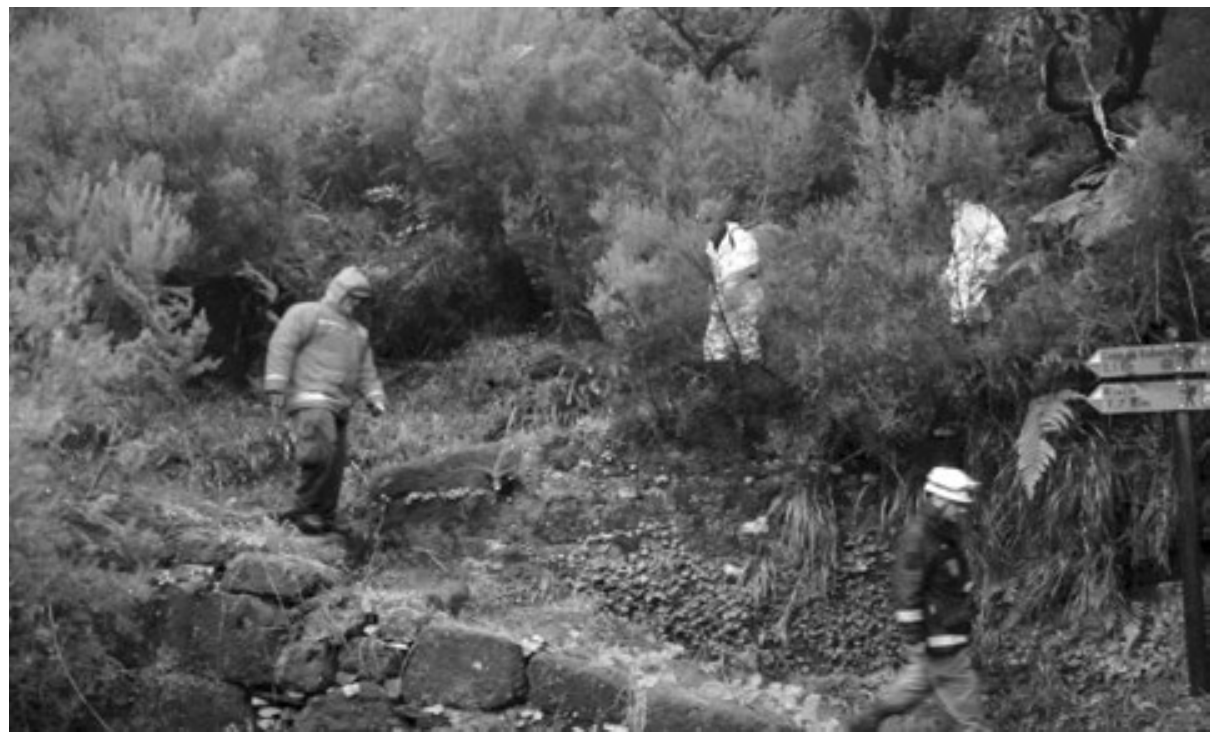

Figura 1 - Operações de Busca e Salvamento em Montanha (SRPC Madeira, 2009)

As caraterísticas geomorfológicas das áreas de montanha estão relacionadas com algumas condições naturais que proporcionam a ocorrência de acidentes. O declive e a forma irregular do terreno, os acessos condicionados e as condições meteorológicas são alguns dos fatores que podem 
condicionar e desencadear esses acidentes. É necessário ter também em conta que as condições naturais vão condicionar as operações de socorro, exigindo, por vezes, o empenho de meios e recursos extraordinários.

Neste contexto, o afluxo de visitantes e praticantes de atividades de turismo natureza e aventura origina, com frequência, situações problemáticas no âmbito da proteção e socorro que exigem, não só o envolvimento e o empenhamento de diversos Agentes de Proteção Civil (APC) que intervêm na região, como também um elevado grau de coordenação e cooperação entre os diferentes agentes.

Importa, pois, definir mecanismos de resposta célere e coordenada no âmbito da proteção e do socorro que permitam fazer face a eventuais situações de perigo. Contudo, para prevenir um acontecimento, há que conhecer as suas causas e as condições necessárias para que tais causas, conjugando-se no espaço e no tempo, possam vir a dar origem a um sinistro.

\section{Riscos e atividades de turismo natureza e aventura na ilha da Madeira}

Como referimos, na Ilha da Madeira, as situações mais críticas estão associadas à desorientação e perda de indivíduos de um determinado grupo. Muitas vezes o afastamento do grupo, mesmo que por poucos instantes, em terrenos desconhecidos, difíceis e com condições meteorológicas adversas, por exemplo com má visibilidade, podem levar a incidentes ou mesmo a acidentes de alguma gravidade. Quando analisamos os fatores que mais contribuem para este tipo de situações, saltam logo à vista as caraterísticas climáticas da ilha, com particular evidência para a ocorrência frequente de nevoeiros em altitude, bem como a existência de muitos topoclimas determinados pela influência do relevo. As pessoas desorientadas podem facilmente ser vítimas de cansaço e de hipotermia, podendo, em casos extremos, ocorrer mesmo a morte. Os fatores naturais que mais facilitam a desorientação são: terreno bastante acidentado e, em certas zonas, com vegetação densa diminuindo a visibilidade; paisagem monótona em alguns setores, criando dificuldades em estabelecer pontos 
de referência; existência de uma extensa área sem vias de comunicação, não obstante a boa sinalização e informação sobre os percursos.
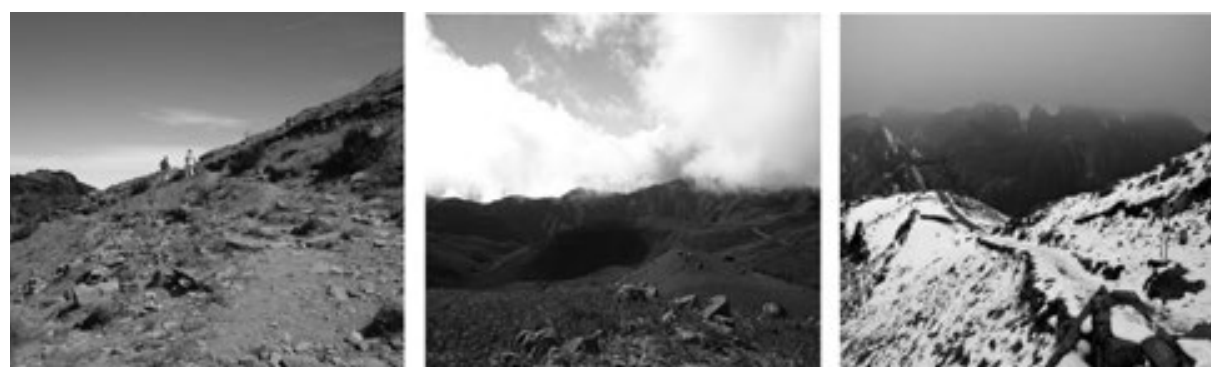

Figura 2 - Fatores desecadeantes de acidentes no Percursos Pedestres

Existem, também, nas áreas em estudo, fatores naturais que propiciam a ocorrência de quedas. A paisagem é marcada pelo acidentado do relevo em que as vertentes são, habitualmente, juncadas de cascalheiras e blocos de diferentes dimensões. Assim, especialmente fora dos caminhos e trilhos marcados, o terreno é bastante irregular, declivoso e juncado de pedras soltas. A ocorrência de chuva e o aumento de humidade junto aos cursos de água tornam os fragmentos de rocha ainda mais escorregadios. A visibilidade reduzida resultante das condições atmosféricas ou da ausência de luz solar, bem como a realização de caminhadas em trilhos bastante irregulares, facilita, também a ocorrência de quedas, que sucedem com frequência, também quando da realização de atividades de aventura. $\mathrm{O}$ acesso a pontos de água para lazer faz-se, em muitas áreas, pelo meio da vegetação, em locais bastante acidentados e de piso irregular, o que concorre para o mesmo efeito.

As quedas podem originar traumatismos de menor ou maior gravidade e, para além disso, podem causar incapacidade ou dificuldade momentânea a nível da mobilidade. Se tal acontecer, e se a zona não permitir acesso a veículos, as vítimas ficam numa situação bastante complexa, uma vez que, mesmo com traumatismos ligeiros, terão grande dificuldade em abandonar o local.

Para além da desorientação e das quedas, devidas sobretudo a comportamentos individuais ou coletivos menos cuidados, há também riscos 
naturais que podem afetar os praticantes que percorram os setores cimeiros da Ilha, como os riscos climáticos (tempestades, nevoeiros, frio súbito), geomorfológicos (desabamentos, deslizamentos e fluxos de terras) ou, mesmo, os incêndios florestais.

Assim sendo, torna-se de vital importância definir e testar ações para minimizar o impato direto ou indireto de eventuais acidentes que venham a ocorrer nas atividades praticadas nas "Veredas e Levadas" da Madeira, que evidenciam poucas alternativas ao nível das acessibilidades rodoviária e pedestre, bem como dificuldades de operação com meios aéreos, sobretudo em situações de reduzida visibilidade, comprometendo a eficácia e/ou eficiência das ações de busca e salvamento, evacuação e respetiva hospitalização.

As principais atividades em matéria de proteção e socorro inerentes aos acidentes derivados da prática dos passeios pedestres ou outras atividades relacionadas, são a busca e resgate de pessoas perdidas ou feridas, bem como o socorro a pessoas em veículos imobilizados devido a condições meteorológicas adversas. Neste âmbito, é crucial definir estratégias de intervenção de nível tático e operacional face à mobilização, prontidão, empenhamento e gestão do emprego de meios e recursos de proteção e socorro nas zonas de intervenção.

Neste domínio, as entidades envolvidas nas operações de proteção e socorro devem garantir o nível adequado de preparação para a emergência, de forma a criar mecanismos de resposta imediata e sustentada, de acordo com o sistema de fluxos de informação horizontal e vertical que permita uma rápida e eficaz mobilização de meios. A rapidez do socorro, a assistência pré-hospitalar e o encaminhamento das vítimas para hospitais de referência são fatores que contribuem decisivamente para o sucesso do salvamento de vítimas de acidentes.

Pelas suas caraterísticas naturais, a Ilha da Madeira apresenta condicionantes naturais que dificultam as operações de socorro. Destacam-se a grande área inacessível a veículos terrestres, a existência de muitos sítios de difícil acesso mesmo para equipas apeadas, o elevado tempo necessário para chegar aos locais e para evacuar pessoas acidentadas; as dificuldades para realizar o alerta e para localizar as vítimas, devido à existência de 
muitos sítios sem rede de telefones móveis em função da morfologia do terreno e, pelo mesmo fator, a própria dificuldade na comunicação entre os agentes que prestam socorro.

De acordo com a codificação e classificação de acidentes e respetivas consequências, definido pela resolução relativa a estatísticas de acidentes, adotado da metodologia utilizada ao nível da segurança e higiene no trabalho, procedeu-se à análise das quedas verificadas no período de 2008 a 2010. As ocorrências registadas foram analisadas segundo a forma do acidente (queda de objetos, esforços excessivos e exposição a temperaturas extremas), segundo a natureza da lesão (lesões superficiais e feridas abertas, fraturas, luxações, distensões e entorses, choque e lesões internas, hipotermia, etc.) e segundo a localização da lesão (cabeça, membros inferiores, membros superiores, corpo inteiro e múltiplos locais).

Conforme o gráfico 1, o maior número de vítimas de acidentes nos percursos pedestres são do sexo feminino (71\%), o que pode estar associado ao défice de resistência, equilíbrio e preparação física para a realização das atividades em circuitos com as caraterísticas anteriormente evidenciadas, quando comparado com os turistas do sexo masculino (29\%).

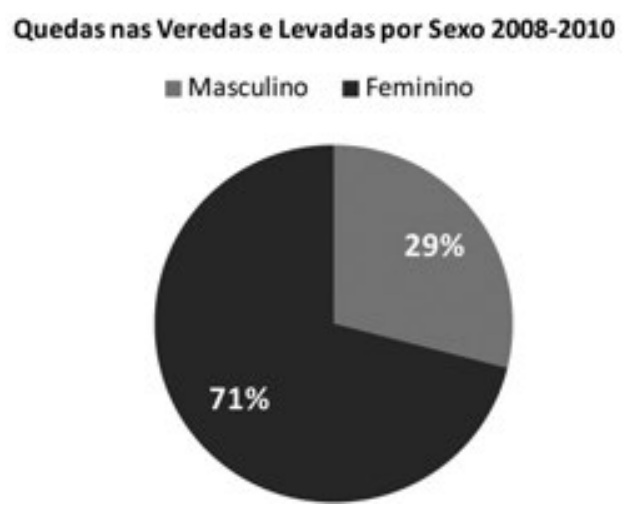

GRÁfICO 1 - Repartição por sexo dos acidentes nas Veredas e Levadas

$\mathrm{Na}$ análise dos acidentes, em função da forma como ocorrem, verifica-se que $67 \%$ estão associados a quedas ao mesmo nível (por vezes por vertigem 
e/ou distração com a beleza das paisagens, bem como pelas condições do piso e de transposição de obstáculos). As restantes quedas, 33\% são em altura, visto que grande parte dos percursos estão expostos a abismos. Grande parte das lesões resultantes das quedas localiza-se nos membros inferiores (67\%), seguindo-se as lesões nos membros superiores (22\%) e na cabeça (11\%), confirmando, assim, a forma do acidente (Gráfico 2).

\section{Forma dos Acidentes Registados nas Levadas}

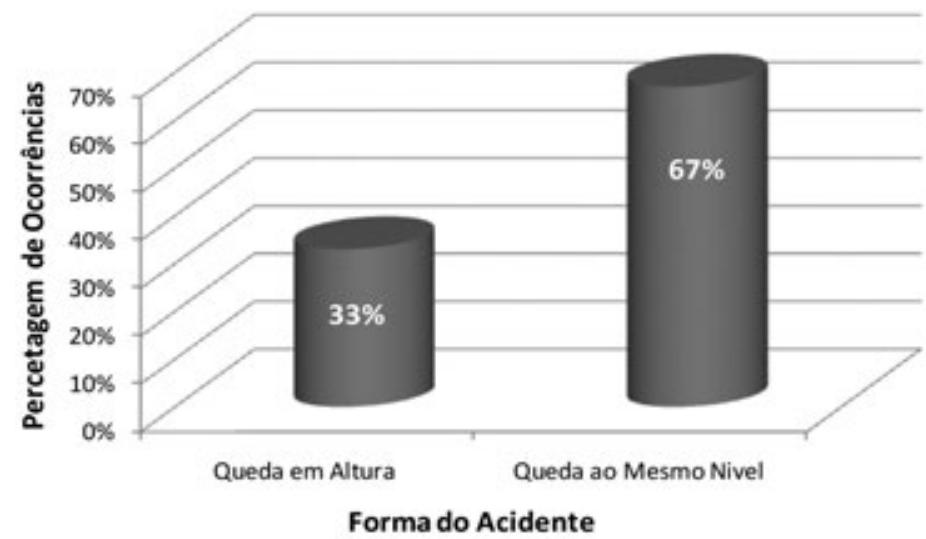

GRÁfICO 2 - Forma dos acidentes nas Levadas e Veredas

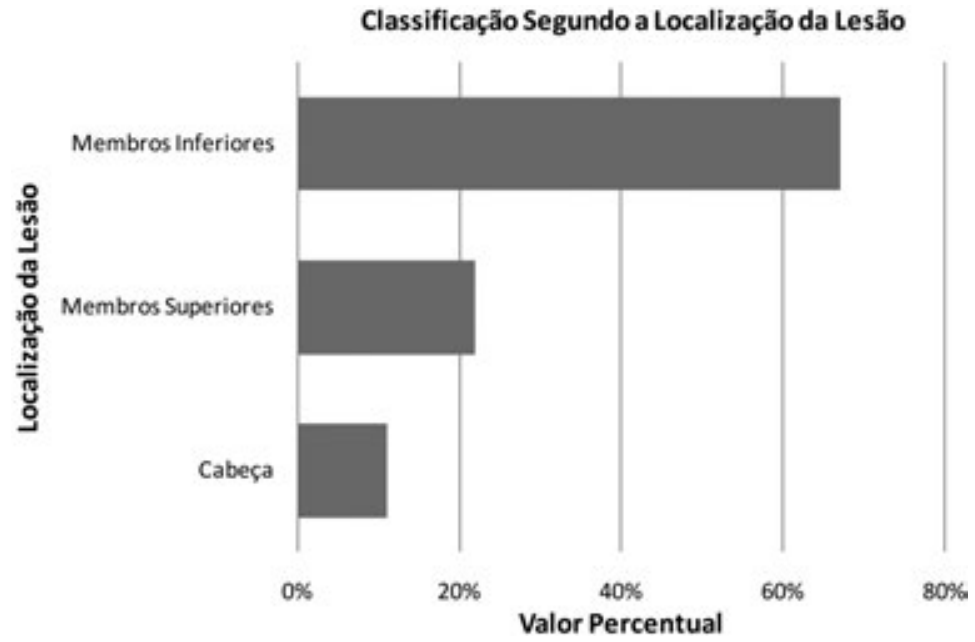

GRÁfICO 3 - Localização das lesões dos acidentes nas Levadas e Veredas 
No que concerne à natureza da lesão, maioritariamente trata-se de fraturas ao nível dos membros inferiores (56\%), seguidas das luxações, distensões e entorses (22\%), lesões superficiais (15\%) e feridas abertas (7\%). Uma nota de destaque na análise do gráfico 4, prende-se com o elevado número de fraturas que condicionam a deslocação dos turistas pelos seus próprios meios, surgindo desta forma o empenhamento de meios de socorro.

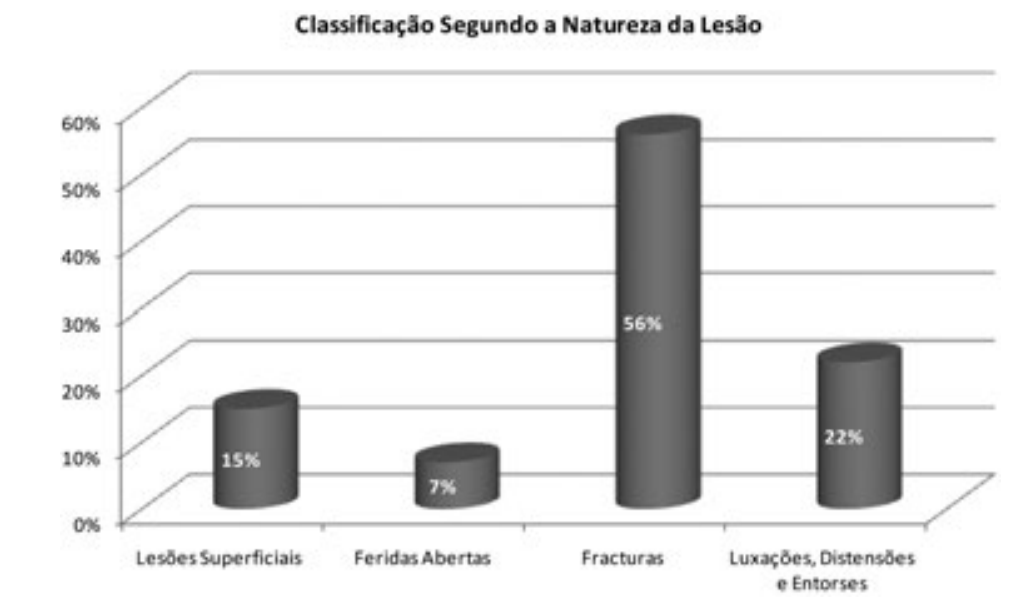

GRÁfico 4 - Classificação dos acidentes segundo a natureza da lesão nos acidentes nas Levadas e Veredas

\section{Conclusão}

No turismo de aventura há riscos evidentes, mas pressupõe-se sempre que o turista tenha sido avisado dos perigos inerentes à atividade que vai praticar. No entanto, persistem ainda acidentes evitáveis, sobretudo os que decorrem de um esforço acima da capacidade física do turista, que pode levar a situações de desidratação ou, mesmo, a problemas cardiovasculares, bem como os pequenos acidentes por desatenção. A falta de preparação de alguns instrutores e a ausência de manutenção dos percursos são, também, causas comuns para os acidentes registados. 
O risco existente para os turistas é impossível de eliminar em absoluto, uma vez que ele é inerente às atividades praticadas. No entanto, este risco pode ser fortemente mitigado através de um conjunto de iniciativas para sensibilizar e incentivar medidas de auto proteção. É importante que os operadores turísticos responsáveis por estas atividades melhorem as condições de segurança dos produtos que oferecem. Outro aspeto fundamental passa pela regulação da atividade, por exemplo com a criação de uma linha de apoio aos utentes em que seja possível dar e receber informações sobre os percursos e atividades a realizar.

No domínio da resposta a situações de emergência, o Serviço Regional Proteção Civil da Madeira nos últimos anos tem levado a cabo vários exercícios de simulacro de resgate e salvamento em montanha, com o intuito de agilizar procedimentos de atuação e de treinar a articulação entre os agentes de Proteção Civil em caso de ocorrência de acidente graves.

O alerta e a localização das pessoas em perigo constituem uma dificuldade acrescida para a prestação de socorro. Neste contexto, a existência de cartografia adequada, bem como a utilização de sinalizadores com GPS são passos importantes para diminuir os tempos de resposta. Neste contexto, considera-se, também, de extrema importância a elaboração de planos prévios de intervenção que permitam, não só uma mais rápida localização dos acidentes, mas também a ativação dos meios mais adequados para socorrer os sinistrados.

Outro aspeto de capital relevância prende-se com o fato de as instituições e entidades públicas e privadas ligadas ao Turismo da Madeira não trabalharem em estreita articulação com os agentes de proteção civil e demais entidades afetas ao dispositivo de proteção e socorro da região. Esta falha terá de ser rapidamente colmatada com o intuito de agilizar procedimentos de planeamento, prevenção e gestão integrada do risco.

Para os turistas que visitam a Ilha da Madeira, a grande questão que se coloca é a de que o descanso e o lazer tão esperados podem transformar-se, subitamente, em situações de dor e angústia, se a segurança não for, de fato, incorporada em todos os pormenores da viagem. Muitas vezes são, se não ocultados, pelo menos pouco divulgados, para não prejudicar a imagem do destino turístico Madeira. No entanto, esta estratégia, a longo 
prazo, acaba por ser pouco útil, na medida em que dificulta o estudo e implementação de medidas para evitar e socorrer casos de novos acidentes.

Os profissionais do turismo têm por obrigação fornecer aos turistas uma informação realista e objetiva sobre os destinos, as condições de viagem, de acolhimento e de estada. Devem também assegurar a transparência perfeita das cláusulas dos contratos propostos aos clientes, quer em matéria da natureza, preço e qualidade dos serviços que se comprometem a fornecer, quer das contrapartidas financeiras que lhes incumbem em caso de rutura unilateral, por sua parte, dos referidos contratos. Nestes contratos as questões de segurança devem ser claramente inscritas, e não omitidas, como quase sempre acontece.

De acordo com os princípios do Código Mundial de Ética do Turismo, as autoridades públicas têm por missão assegurar a proteção dos turistas e dos seus bens. Devem conceder especial atenção à segurança dos turistas estrangeiros, por causa da sua particular vulnerabilidade e devem disponibilizar-lhes meios específicos de informação, de prevenção, de proteção, de seguros e de assistência. Por outro lado, os atentados, agressões, raptos ou ameaças visando os turistas e os trabalhadores da indústria turística, bem como as destruições voluntárias de instalações turísticas ou de elementos do património cultural ou natural, devem ser severamente condenadas e reprimidas, em conformidade com as respetivas legislações nacionais.

Como exercício final, considerando os impates resultantes dos 2 grandes desastres que ocorreram na Ilha da Madeira em 2010 (Aluvião de 20 Fevereiro e os incêndios florestais com início a 13 de Agosto), as questões de segurança mostram-se absolutamente fundamentais para a consolidação dos destinos e dos produtos turísticos. Saliente-se que estes eventos potenciaram uma discussão político-social em torno do risco, nomeadamente no que diz respeito à vulnerabilidade do setor do turismo, pelo fato de a segurança constituir uma variável incontornável nesta atividade e ser hoje preponderante a escolha do destino também em função da imagem de segurança a nível físico, psicológico e material que este oferece. 


\section{Referências bibliográficas}

Alexander, D. 2002, Principles of emergency planning and management. New York: Oxford University Press.

Ayala, Carcedo, F. J. 2002, Introducción al análisis y gestión de riesgos, in Cantos, Jorge Olcina e Ayala - Carcedo, Francisco Javier (Ed.) - Riesgos naturales. Barcelona: Ariel Ciência.

AYorA, A. 2008, Gestion Del Riesgo en Montaña y en actividades al Aire libre, ediciones desnível.

BECK, U. 1992, Risk society. Towards a new modernity. London: Sage.

BEEDIE, P. 2003, Adventure Tourism: Sport and adventures tourism, Edited bySimon Hudson. New York: The Haworth Hospitality Press.

Brasil 2005, Turismo de Aventura: Busca e Salvamento. Manual de criação e organização de grupos voluntários de busca e salvamento. Brasília: Ministério do Turismo.

Cabral, F. 2006, Higiene, Segurança, Saúde e Prevenção de Acidentes, Verlag Dashofer Edições Profissionais, Lda.

Comité 0B-007 Gestão De Riscos 2004, Standards Austrália e Standards New Zealand:Norma AS/NZS: 4360. São Paulo: Coleção Risk tecnologia.

Cooper, Dale; Grey, S.; Raymond, G.; Walker, P. 2005, Project risk management guidelines - managing risk in large projects and complex procurement, Wiley: England.

Cunha, Lúcio; Cravidão, Fernanda Delgado, 1998, Notas para uma geografia dos desportos radicais em Portugal, Inforgeo.

Curbet, J. 2005, Turismo y Seguridad: una relación de amor-odio, Seguridad Sostenible, [on line], Edición 25, Disponível em: www.iigov.org/ss/article.

Grunewald, L. 2001, Seguridad: Manual de Pautas de Seguridad para el Residente y el Visitante de un Destino Turístico, Disponível em: http://www.paph-oea-cct.com/.

Hamaué, S. 2008, Gestão de riscos aplicada à segurança do turismo de Aventura. São Paulo: Dissertação de Doutoramento.

Hоlсомв, J. e PIZAm, А. 2006, Do Incidents of theft at tourist destinations have a negative effect on tourists' decisions to travel to affected destinations, in $\mathrm{Y}$. 
Mansfeld e A. Pizam (eds.) Tourism, Security \& Safety: From Theory to Practice, Oxford: Butterworth-Heinemann, pp. 105-124.

HOOD C. 2001, The government of risk: understanding risk regulation regimes. Oxford: University Press.

Hudson, S. 2003, Sport and Adventure Tourism, PhD Editor. New York, London, Oxford: The Haworth Hospitality Press.

Information In Tourism Crisis Management: The Missing Link”, in Y. Mansfeld e A. Pizam (eds.),Tourism, Security \& Safety: From Theory to Practice. Oxford: Butterworth-Heinemann, pp. 271-290.

Morales, S. 2002, Análisis del Concepto de Seguridad Turística, Disponível em: http://www.integrando.org.ar/turismo/seguridad 01.htm.

Neves, D., 2010, Turismo e Riscos na Ilha da Madeira. Avaliação, perceção, estratégias de planeamento e prevenção. Coimbra: Diss. Mestrado em Dinâmicas Sociais e Riscos Naturais e Tecnológicos.

Pizam, A. e Mansfeld, Y. 2006, Toward a Theory of Tourism Security, in Y. Mansfeld e A. Pizam (eds.),Tourism, Security \& Safety: From Theory to Practice. Oxford: Butterworth-Heinemann, pp. 1-27.

Quintal, R. 2003, Madeira, à Descoberta da Ilha de Carro e a Pé, 1. ${ }^{a}$ edição. Funchal: Associação dos Amigos do Parque Ecológico do Funchal.

Ramos, Ricardo Jorge, 2001, Actividades Físicas de Aventura na Natureza. Legislação numa Óptica não Profissional. Coimbra: FCDEF.

Roehl, W. e Fesenmeir, D. 1992, Risk Perception and Pleasure Travel: An Explanatory Analysis, in: Journal of Travel Research. 